\title{
ÚNG DỤNG THANG ĐIỂM ESSEN TRONG TIÊN LƯợNG BỆNH NHÂN CHẢY MÁU NÃO
}

Nguyễn Đình Toàn; Ksorr Nguyễn Kiều My Trường Đại học Y Dượ, Đại học Hué

DOI: $10.47122 / v j d e .2020 .44 .9$

\section{TÓM TẮT}

Đặt vấn đề: Chảy máu não có tỉ lệ tử vong tại bệnh viện cao nhất trong các thể đột quy, kết cục chức năng tốt chỉ đạt được khoảng 12$39 \%$ bệnh nhân. Mặc dù có nhiều thang điểm tiên lượng chảy máu não nhưng đa số đều tập trung tiên lượng tử vong, trên thế giới và trong nước ít có nghiên cứu tiên lượng hồi phục sau chảy máu não. Năm 2006 Weimar và cộng sự đã phát triển và chứng minh giá trị tiên lượng của một thang điểm mới- thang điểm Essen với điểm mạnh của nó trong tiên lượng hồi phục ở bệnh nhân chảy máu não. Tuy nhiên, thang điểm này cần được kiểm tra và xác nhận trong những quần thể khác nhau và đối chứng với những thang điểm khác để xác minh giá trị tiên lượng của nó, tại Việt Nam chưa có nghiên cứu nào đánh giá ý nghĩa của thang điểm chảy máu não Essen trong tiên lượng tử vong và hồi phục của bệnh nhân chảy máu não sau 100 ngày, vì vậy chúng tôi thực hiện đề tài "Nghiên cứu tiên lượng bệnh nhân chảy máu não tự phát bằng thang điểm chảy máu não Essen tại bệnh viện Trung ương Huế" với 2 hai mục tiêu: (1) Đánh giá các yếu tố của thang điểm chảy máu não Essen trong tiên lượng bệnh nhân chảy máu não. (2) Khảo sát mối liên quan, tương quan giữa giá trị tiên lượng bằng thang điểm Essen $\mathrm{ICH}$ với giá trị tiên lượng của một số yếu tố lâm sàng và so với thang điểm $\mathrm{ICH}$, thang điểm mICH. Đối tượng và phương pháp nghiên cứu: Nghiên cứu mô tả cắt ngang, có theo dõi dọc trên 120 bệnh nhân chảy máu não tự phát tại Bệnh viên Trung ương Huế từ tháng 01/2019 đến tháng 01/2020. Các bệnh nhân chảy máu não khởi phát trong vòng 24 giờ đầu tiên được thăm khám trực tiếp, tính các thang điểm Essen (gồm ba thành tố: tuổi, NIHSS, mức độ ý thức theo NIHSS) và các thông số lâm sàng, cận lâm sàng khác. Thu thập thông tin về kết cục chức năng của bệnh nhân tại thời điểm 100 ngày sau khởi bệnh bằng phương pháp phỏng vấn qua điện thoại. Số liệu được phân tích bằng phần mềm SPSS 20.0. Hồi quy logistic được sử dụng để xác định yếu tố tiên lượng độc lập. Giá trị thang điểm được xác định bởi đường cong ROC. Kết quả: Trong 120 bệnh nhân, tuổi trung bình là $64,32 \pm 13,625$, điểm NIHSS trung bình $15,17 \pm$ $10,793,43,3 \%$ bệnh nhân có điểm ý thức theo NIHSS là 0 . Essen $\mathrm{ICH}=0$ có $93,8 \%$ bệnh nhân hồi phục hoàn toàn, và với $\mathrm{ICH} \geq 7100 \%$ tử vong. Essen $\mathrm{ICH}$ cho thấy có giá trị cao trong tiên lượng kết cục tàn tật và tử vong. Trong tiên lượng kết cục tàn tật theo thang điểm Barthel sau 100 ngày, Essen $\mathrm{ICH}$ tỏ ra vượt trội hơn so với $\mathrm{ICH}$ và $\mathrm{mICH}$ (AUC lần lượt: Essen ICH: 0,934 (95\%CI 0,893-0,975); ICH: $\quad 0,882 \quad(95 \% \mathrm{CI} \quad 0,823-0,942)$; $\mathrm{mICH}$ : 0,896 (95\%CI 0,842-0,951). Kết luận: Essen ICH là thang điểm dễ sử dụng cho tiên lượng bệnh nhân chảy máu não. Nó có giá trị rất cao trong tiên lượng kết cục chức năng không tốt và dễ dàng sử dụng trong tiên lượng cá nhân hoặc thiết kế nghiên cứu lâm sàng.

Tù khóa: thang điểm Essen, chảy máu não

\section{ABSTRACT \\ Predicting spontaneous intracerebral hemorrhage by the essen ich score at Hue Central Hospital}

Nguyen Dinh Toan, Ksor Nguyen Kieu My University of Medicine and Pharmacy, Hue University

Background: Intracerebral haemorrhage (ICH) accounts for the highest of hospital mortality of all stroke types, outcome is favourable in about $12-39 \%$ of patients. Despite several existing outcome prediction models for ICH, most of them to predict the hospital mortality but only some models for prediction the complete outcome after 100 
days ICH. At 2006, Weimar was development and validationof the Essen intracerebral haemorrhage score which was a high prognostic accuracy for adverse outcomes and death in patients with ICH. In Viet Nam, there is no study determine Essen ICH score value. The aim of this study is evaluate the Essen ICH score for prediction of the outcome (BI) in patients after 100 day with spontaneous intracerebral haemorrhage. Subject and methods: Descriptive and progressive research. The study described 120 patients with spontaneous intracerebral haemorrhage at Hue Central Hospital from 01/2019-01/2020. The patients were assessed on the Essen ICH (include: age, NIHSS, NIHSS LOC) and other factor on 24 hours onset and after follow up of 100 days. Statistical analysis was carried out with the program package SPSS version 20.0. Logistic was used to determination of independent factor and score value was determined by ROC curve. Results: Among the 120 patients, median age was

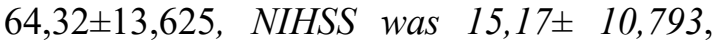
$43,3 \%$ patients with NIHSS LOC was 0 . Essen $\mathrm{ICH}=0$ about 93,8\% patients complete recovery and with Essen $\mathrm{ICH} \geq 7$ had100\% death. The Essen ICH score showed a high prognostic accuracy for adverse outcomes and death. For prediction of adverse outcomes on the Barthel index after 100 days, the Essen ICH score was superior to the $\mathrm{ICH}$ and $\mathrm{mICH}$ (AUC: Essen ICH: 0,934 $(95 \% \mathrm{CI} \quad 0,893-$ 0,975); ICH: $0,882 \quad(95 \% \mathrm{CI} \quad 0,823-0,942)$; mICH: $\quad 0,896 \quad(95 \% \mathrm{CI} \quad 0,842-0,951)$. Conclusions: The Essen ICH score provides an easy way to use scale for outcome prediction following $\mathrm{ICH}$. Its high positive predictive values for adverse outcomes and easy applicability render it useful for individual prognostic indications or the design of clinical studies.

Key words: Essen ICH, Intracerebral hemorrhage

Chịu trách nhiệm chính: Nguyễn Đình Toàn

Ngày nhận bài: 02/11/2020

Ngày phản biện khoa học: 08/12/2020

Ngày duyệt bài: 29/01/2021
Email: dinhtoan73@gmail.com

Điện thoại: 0914000066

\section{1. ĐẶT VẤN ĐỀ}

Chảy máu não tuy chỉ gặp ở khoảng $10 \%$ bệnh nhân đột quỵ nhưng lại có tỉ lệ tử vong cao hoặc để lại di chứng lâu dài, chỉ 12-39\% bệnh nhân sống sót có được kết cục độc lập lâu dài [2], [3]. Do đó mà vấn đề tiên lượng một bệnh nhân sau chảy máu não ngày càng được quan tâm, nhìn nhận một cách khách quan, chính xác nhất có thể nhằm giúp cho việc lựa chọn phác đồ điều trị thích hợp, theo dõi bệnh nhân, phân nhóm bệnh nhân cho các thử nghiệm lâm sàng, so sánh kết quả điều trị cũng như đánh giá hiệu quả của các ứng dụng mới trong điều trị bệnh. Tiên lượng chảy máu não đã được nghiên cứu từ những năm 1990 với những công trình nghiên cứu như của Castilo, Boderick đã tìm ra những yếu tố lâm sàng có giá trị tiên lượng tử vong ở bệnh nhân chảy máu não như tuổi, điểm Glasgow, thể tích khối máu tụ lớn, chảy máu não thất, chảy máu dưới lều..... [4], [8]. Và sau đó là sự ra đời của các thang điểm tiên lượng như $\mathrm{ICH}$, và các biến thể của nó như $\mathrm{mICH}, \mathrm{ICH}-\mathrm{GS}$, ICH-FOS, thang điểm FUNC,..tuy nhiên đa số đều tập trung tiên lượng tử vong, chỉ có mICH có khả năng phân biệt giữa các nhóm kết cục chức năng [6]. Nhận thấy vai trò lợi ích của việc tiên lượng dành cho những bệnh nhân có tiên lượng tốt hơn, những bệnh nhân còn sống, còn kì vọng về các mức độ hồi phục bên cạnh việc dự đoán của các nhà lâm sàng tỏ ra khá bi quan và những chăm sóc không tích cực có thể xảy ra ở những bệnh nhân có tiên lượng xấu [9], [10], [11] cho nên vào năm 2006 Weimar và cộng sự đã phát triển và chứng minh giá trị tiên lượng của một thang điểm mới- thang điểm Essen với điểm mạnh của nó trong tiên lượng hồi phục ở bệnh nhân chảy máu não. Tuy nhiên, thang điểm này cần được kiểm tra và xác nhận trong những quần thể khác nhau và đối chứng với những thang điểm khác để xác minh giá trị tiên lượng của nó, tại Việt Nam chưa có nghiên cứu nào đánh giá ý nghĩa của thang điểm chảy máu não Essen trong tiên lượng tử vong và hồi phục của bệnh nhân chảy máu não sau 100 ngày, vì 
vậy chúng tôi thực hiện đề tài "Nghiên cứu tiên lự̣ng bệnh nhân chảy máu não tụ" phát bằng thang điểm chảy máu não Essen tại Bệnh viện Trung uơng Huế" với 2 hai mục tiêu:

1. Đánh giá các yếu tố của thang điểm chảy máu não Essen trong tiên lượng bệnh nhân chảy máu não.

2. Khảo sát mối liên quan, tương quan giũa giá trị tiên lương bằng thang điểm Essen ICH với giá trị tiên lượng của một số yếu tố lâm sàng và so với thang điểm $I C H$, thang điểm $\mathrm{mICH}$.

\section{2. ĐỐI TƯợNG VÀ PHƯƠNG PHÁP NGHIÊN CÚU}

Nghiên cứu mô tả cắt ngang, tiến cứu, có theo dõi dọc được tiến hành trên 120 bệnh nhân chảy máu não tự phát tại khoa Hồi sức tích cực và Khoa Đột quỵ Bệnh viện Trung ương Huế từ tháng $01 / 2019$ đến tháng $01 / 2020$. Với tiêu chuẩn chọn bệnh là bệnh nhân được chẩn đoán đột quỵ theo định nghĩa của tổ chức y tế thế giới “ dấu chứng rối loạn chức năng vỏ não khu trú hoặc toàn thể tiến triển nhanh kéo dài hơn $24 \mathrm{~h}$ và không có nguyên nhân rõ ràng nào khác ngoài nguồn gốc mạch máu". Kèm theo hình ảnh tăng tỉ trọng trong nhu mô não trên phim CT scan từ 56-90 đơn vị Hounsfield [1], thời gian từ khi khởi phát bệnh hoặc thời điểm cuối cùng bệnh nhân còn thấy bình thường đến khi được chọn vào nghiên cứu trong vòng 24 giờ. Những bệnh nhân hoặc người nhà bệnh nhân không đồng ý tham gia nghiên cứu, bệnh nhân chảy máu não thứ phát, chảy máu não do chấn thương sọ não, và bệnh nhân có những bệnh lí nặng có thể ảnh hưởng đến tiên lượng không được đưa vào nghiên cứu.

Các bệnh nhân đủ tiêu chuẩn lựa chọn sẽ được người nghiên cứu trực tiếp phỏng vấn bệnh nhân hoặc người nhà nếu bệnh nhân không tiếp xúc được về tiền sử, bệnh sử, khám lâm sàng và thu thập dữ liệu hình ảnh trên phim chụp cắt lớp sọ não và thông tin bệnh nhân trên hồ sơ bệnh án để thu thập các thông số, ghi ngay tại chỗ vào phiếu nghiên cứu trong vòng 24 giờ đầu sau khởi phát bệnh. Bao gồm: tuổi, giới, tiền sử; huyết áp: huyết áp thời điểm nhập viện của bệnh nhân được lấy từ kết quả đo huyết áp tại phòng cấp cứu; kết quả CTScan theo hồ sơ bệnh án; đánh giá mức độ nặng của đột quỵ theo thang điểm NIHSS. Các thông tin thu thập được quy đổi về thang điểm Essen $\mathrm{ICH}, \mathrm{ICH}$ và mICH. Đánh giá kết cục chức năng của bệnh nhân sau 100 ngày khởi bệnh bằng hỏi bệnh qua điện thoại trực tiếp bệnh nhân hay người thân bệnh nhân theo thang điểm Barthel.

Tất cả số liệu trong nghiên cứu được phân tích bằng phần mềm SPSS 20.0. Các biến định tính được trình bày theo tỉ lệ phần trăm, so sánh các tỉ lệ bằng test $\chi 2$. Đối với biến định lượng, so sánh hai trung bình bằng kiểm định $\mathrm{T}$-test. Phân tích hồi quy logistics đơn biến và đa biến đối với tất cả các biến số nghiên cứu để tìm yếu tố tiên lượng độc lập với kết cục tử vong và kết cục tàn tật sau 100 ngày khởi bệnh. Đường cong ROC được tạo ra thể hiện giá trị tiên lượng của từng thang điểm.

\section{KẾT QUẢ NGHIÊN CÚU}

Qua nghiên cứu 120 bệnh nhân chảy máu não nhập viện điều trị tại Bệnh viện Trung ương Huế từ $01 / 2019$ đến $01 / 2020$, chúng tôi thu được một số kết quả như sau:

\section{1. Đặc điểm chung của đối tượng nghiên cứu}

Trong số 120 bệnh nhân tham gia nghiên cứu, tỉ lệ tử vong là $50,8 \%$, có $30,8 \%$ bệnh nhân hồi phục hoàn toàn theo thang điểm Barthel tại thời điểm 100 ngày. Qua các thuật toán thống kê mô tả, một số đặc điểm chung của đối tượng nghiên cứu được thể hiện trong bảng 3.1. Qua đây, có sự khác biệt về kết cục chức năng tại thời điểm 100 ngày ở những bệnh nhân có huyết áp tâm thu lúc vào viện cao dần, điểm Glasgow lúc vào viện thấp dần, có chảy máu não thất, thể tích khối máu tụ trên $30 \mathrm{~cm}^{3}$, điểm Essen, $\mathrm{ICH}$ và $\mathrm{mICH}$ tăng dần. Sự khác biệt có ý nghĩa thống kê với mức ý nghĩa $\mathrm{p}<0,05$. 
Bảng 3.1. Đặc điểm chung của đối tượng nghiên cứu

\begin{tabular}{|c|c|c|c|c|c|c|}
\hline \multicolumn{2}{|c|}{ Nô̂i dung chức năng } & $\begin{array}{l}\text { Hồi phục } \\
\text { hoàn toàn }\end{array}$ & $\begin{array}{l}\text { Phụ thuộc } \\
\text { trung bình }\end{array}$ & $\begin{array}{c}\text { Phụ thuộc } \\
\text { nặng }\end{array}$ & Tử vong & $\mathbf{p}$ \\
\hline \multicolumn{2}{|l|}{ Tuổi } & $59,22 \pm 12,972$ & $64,31 \pm 10,136$ & $69,33 \pm 15,716$ & $66,6 \pm 13,721$ & $\mathbf{0 , 0 3 9}$ \\
\hline \multirow[t]{2}{*}{ Giới } & Nam & $67,6 \%$ & $30,8 \%$ & $33.3 \%$ & $62,3 \%$ & \multirow{2}{*}{0,045} \\
\hline & Nũ & $32,4 \%$ & $69,2 \%$ & $66,7 \%$ & $37,7 \%$ & \\
\hline \multirow[t]{3}{*}{ Tiền sử } & THA & $73 \%$ & $53,8 \%$ & $66,7 \%$ & $65,6 \%$ & 0,647 \\
\hline & ĐТÐ & $97,3 \%$ & $100 \%$ & $100 \%$ & $93,4 \%$ & 0,567 \\
\hline & TBMMN & $13,5 \%$ & $0 \%$ & $0 \%$ & $16,4 \%$ & 0,259 \\
\hline \multirow{3}{*}{$\begin{array}{l}\text { Glasgow } \\
\text { vào viện }\end{array}$} & $3-4$ & 0 & 0 & 0 & 100 & \multirow{3}{*}{$<0,001$} \\
\hline & $5-12$ & 12,9 & 12,9 & 2,9 & 71,4 & \\
\hline & 13-15 & 60,9 & 8,7 & 15,2 & 15,2 & \\
\hline \multicolumn{2}{|c|}{ HATT (mmHg) } & $156,76 \pm 27,188$ & $159,62 \pm 33,321$ & $151,11 \pm 28,916$ & $179,66 \pm 41,302$ & $\mathbf{0 , 0 0 7}$ \\
\hline \multicolumn{2}{|c|}{ HATTr (mmHg) } & $89,73 \pm 13,64$ & $88,46 \pm 14,632$ & $86,67 \pm 15,811$ & $95,57 \pm 15,867$ & 0,115 \\
\hline \multicolumn{2}{|c|}{ Chảy máu não thất } & $27 \%$ & $23,1 \%$ & $44,4 \%$ & $75,4 \%$ & $<0,001$ \\
\hline \multicolumn{2}{|c|}{ Chảy máu dưới lều } & $8,1 \%$ & $0 \%$ & $0 \%$ & $16,4 \%$ & 0,17 \\
\hline \multicolumn{2}{|c|}{$\begin{array}{l}\text { Thể tích khối máu tụ } \\
\geq 30 \mathrm{~cm}^{3}\end{array}$} & $18,9 \%$ & $38,5 \%$ & $33,3 \%$ & $62,3 \%$ & $<0,001$ \\
\hline \multicolumn{2}{|c|}{ NIHSS } & 4,11 & 8,62 & 11,22 & 23,84 & $<0,001$ \\
\hline \multicolumn{2}{|c|}{ Essen ICH } & 1,19 & 2,85 & 3,22 & 7,07 & $<0,001$ \\
\hline \multicolumn{2}{|c|}{$\mathrm{ICH}$} & $0,65 \pm 0,633$ & $1,23 \pm 1,363$ & $1,11 \pm 0,782$ & $3,15 \pm 1,014$ & $<0,001$ \\
\hline \multicolumn{2}{|l|}{$\mathrm{mICH}$} & $0,59 \pm 0,599$ & $1 \pm 1,155$ & $1,56 \pm 0,726$ & $3,34 \pm 1,047$ & $<0,001$ \\
\hline
\end{tabular}

\subsection{Giá trị tiên lượng của các thành tố trong thang điểm Essen}

Chúng tôi tiến hành phân tích hồi quy logistics đơn biến và đa biến từng yếu tố trong thang điểm Essen lần lượt với kết cục tử vong và kết cục tàn tật để xác định giá trị tiên lượng của chúng với hai loại kết cục này, kết quả được trình bày ở bảng 3.2 và 3.3. Kết quả cho thấy trong ba yếu tố của thang điểm Essen thì tuổi và điểm NIHSS là yếu tố tiên lượng độc lập kết cục tàn tật, trong khi điểm NIHSS và mức độ ý thức theo NIHSS là yếu tố tiên lượng độc lập với kết cục tử vong. Trong ba yếu tố này thì điểm NIHSS là yếu tố có giá trị nhất trong cả tiên lượng kết cục tử vong lẫn tàn tật.

Bảng 3.2. Kết quả phân tích hồi quy logistic đơn biến các yếu tố trong thang điểm Essen với kết cục chức năng tại thời điểm 100 ngày

\begin{tabular}{|l|c|c|c|c|c|c|}
\hline \multirow{2}{*}{ Yếu tố } & \multicolumn{3}{|c|}{ Tiên lượng tử vong } & \multicolumn{3}{c|}{ Tiên lượng tàn tật } \\
\cline { 2 - 7 } & $\mathbf{O R}$ & $\mathbf{9 5 \%} \mathbf{C I}$ & $\mathbf{p}$ & $\mathbf{O R}$ & $\mathbf{9 5 \%} \mathbf{C I}$ & $\mathbf{p}$ \\
\hline Tuổi & 1,027 & $0,999-1,056$ & 0,056 & 1,046 & $1,000-1,094$ & $\mathbf{0 , 0 4 9}$ \\
\hline NIHSS & 1,444 & $1,256-1,660$ & $<\mathbf{0 , 0 0 1}$ & 1,53 & $1,226-1,910$ & $<\mathbf{0 , 0 0 1}$ \\
\hline $\begin{array}{l}\text { Mức độ ý } \\
\text { thức NIHSS }\end{array}$ & 7,968 & $4,070-15,601$ & $<\mathbf{0 , 0 0 1}$ & 2,586 & $0,877-7,623$ & 0,085 \\
\hline
\end{tabular}


Bảng 3.3. Kết quả phân tích hồi quy logistic đa biến các yếu tố trong thang điểm Essen với kết cục chức năng tại thời điểm 100 ngày

\begin{tabular}{|l|c|c|c|c|c|c|}
\hline \multirow{2}{*}{ Yếu tố } & \multicolumn{3}{|c|}{ Tiên lượng tử vong } & \multicolumn{3}{c|}{ Tiên lượng tàn tật } \\
\cline { 2 - 7 } & OR & $\mathbf{9 5 \% C I}$ & $\mathbf{p}$ & OR & $\mathbf{9 5 \%} \mathbf{C I}$ & $\mathbf{p}$ \\
\hline Tuổi & 1,014 & $0,963-1,067$ & 0,599 & 1,010 & $0,953-1,070$ & 0,744 \\
\hline NIHSS & 6,447 & $3,513-11,832$ & $<0,001$ & 10,581 & $2,875-38,945$ & $\mathbf{0 , 0 0 2}$ \\
\hline
\end{tabular}

\subsection{Mối liên quan, tương quan của thang điểm Essen và một số yếu tố khác}

(a)

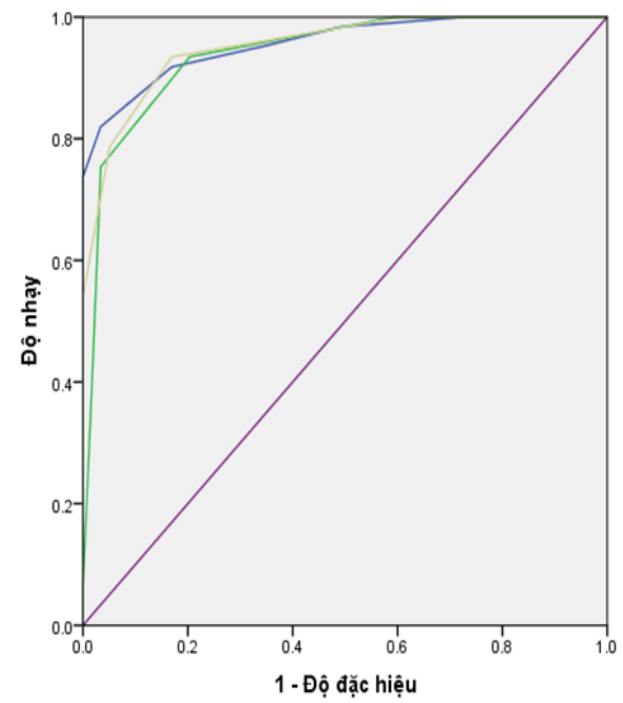

(b)

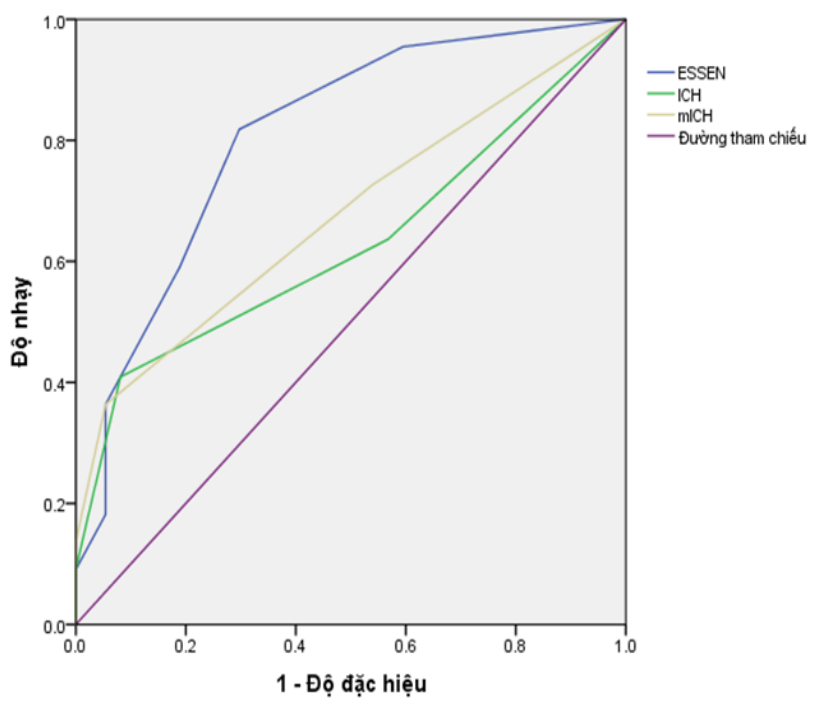

Sơ đồ 1.1. Đường cong ROC thể hiện giá trị tiên lượng của các thang điểm tại thời điểm 100 ngày

Ghi chú: (a). Các thang điểm trong tiên lượng tử vong

(b). Các thang điểm trong tiên lượng tàn tật.

Bảng 3.4. Giá trị tiên lượng của các thang điểm tại thời điểm 100 ngày

\begin{tabular}{|c|c|c|c|c|c|c|}
\hline \multirow{2}{*}{} & \multicolumn{3}{|c|}{ Tiên lự̛ng tử vong } & \multicolumn{3}{c|}{ Tiên lương tàn tật } \\
\cline { 2 - 7 } & Essen & ICH & mICH & Essen & ICH & $\mathrm{mICH}$ \\
\hline AUC & 0,957 & 0,941 & 0,952 & 0,934 & 0,882 & 0,896 \\
\hline Điểm cắt & 5,5 & 2,5 & 2,5 & 3,5 & 1,5 & 1,5 \\
\hline Độ nhạy & $82 \%$ & $77 \%$ & $78,7 \%$ & $77,1 \%$ & $79,5 \%$ & $78,3 \%$ \\
\hline Độ đặc hiệu & $96,6 \%$ & $96,6 \%$ & $96,6 \%$ & $94,6 \%$ & $91,9 \%$ & $94,6 \%$ \\
\hline $\begin{array}{c}\text { Giá trị dự đoán } \\
\text { dương }\end{array}$ & $96,2 \%$ & $95,9 \%$ & $96 \%$ & $97 \%$ & $95,7 \%$ & $97 \%$ \\
\hline Giá trị dự đoán âm & $83,8 \%$ & $80,3 \%$ & $81,4 \%$ & $64,8 \%$ & $66,7 \%$ & $66 \%$ \\
\hline Chỉ số Youden & 0,786 & 0,737 & 0,753 & 0,717 & 0,714 & 0,729 \\
\hline p & $<0,001$ & $<0,001$ & $<0,001$ & $<0,001$ & $<0,001$ & $<0,001$ \\
\hline 95\%CI & 0,924 & 0,899 & 0,918 & 0,893 & 0,823 & 0,842 \\
& $-0,989$ & $-0,982$ & $-0,986$ & $-0,975$ & $-0,942$ & $-0,951$ \\
\hline
\end{tabular}

Kết quả phân tích hồi quy logistic đơn biến để tìm các yếu tố tiên lượng độc lập kết cục chức năng tại thời điểm 100 ngày được trình bày ở bảng 3.5 cho thấy các yếu tố tiên lượng tử vong bao 
gổm: Huyết áp tâm thu, huyết áp tâm trương, điểm Glasgow lúc vào viện, thể tích khối máu tụ trên $30 \mathrm{~cm}^{3}$, chảy máu não thất, và điểm Essen. Các yếu tố tiên lượng độc lập kết cục tàn tật tại thời điểm 100 ngày bao gồm: tuổi, giới, điểm Glasgow lúc vào viện, và điểm Essen.

Các yếu tố tiên lượng độc lập trong phân tích hồi quy logistc đơn biến được đưa vào hồi quy logistic đa biến, kết quả được trình bày trong bảng 3.6. Kết quả này cho thấy: thang điểm Essen là yếu tố tiên lượng kết cục tử vong và tàn tật tại thời điểm 100 ngày.

Bảng 3.5. Kết quả phân tích hồi quy logistic đơn biến các yếu tố tiên lượng độc lập kết cục chức năng tại thời điểm 100 ngày

\begin{tabular}{|l|c|c|c|c|c|c|}
\hline \multirow{2}{*}{\multicolumn{1}{c|}{ Yếu tố }} & \multicolumn{3}{|c|}{ Tiên lượng tử vong } & \multicolumn{3}{c|}{ Tiên lượng tàn tật } \\
\cline { 2 - 7 } & $\mathbf{O R}$ & $\mathbf{9 5 \%} \% \mathbf{C I}$ & $\mathbf{P}$ & $\mathbf{O R}$ & $\mathbf{9 5 \% C I}$ & $\mathbf{P}$ \\
\hline Tuồi & 1,027 & $0,999-1,056$ & 0,056 & 1,046 & $1-1,094$ & $\mathbf{0 , 0 4 9}$ \\
\hline Giới & 1,394 & $0,673-2,888$ & 0,371 & 0,224 & $0,072-0,694$ & $\mathbf{0 , 0 1}$ \\
\hline Huyết áp tâm thu & 1,019 & $1,007-1,030$ & $\mathbf{0 , 0 0 1}$ & 0,999 & $0,981-1,018$ & 0,935 \\
\hline Huyết áp tâm trương & 1,030 & $1,005-1,057$ & $\mathbf{0 , 0 2}$ & & & \\
\hline Glasgow lúc vào viện & 0,069 & $0,027-0,178$ & $<\mathbf{0 , 0 0 1}$ & 0,664 & $0,495-0,890$ & $\mathbf{0 , 0 0 6}$ \\
\hline Thể tích khối máu tụ & 4,846 & $1,017-1,046$ & $<\mathbf{0 , 0 0 1}$ & 0,408 & $0,123-1,351$ & 0,142 \\
\hline Chảy máu não thất & 7,576 & $3,369-17,041$ & $<\mathbf{0 , 0 0 1}$ & 0,794 & $0,250-2,516$ & 0,695 \\
\hline Chảy máu dưới lều & 3,660 & $0,954-14,046$ & 0,059 & & & \\
\hline Điểm Essen & 2,688 & $1,942-3,719$ & $<\mathbf{0 , 0 0 1}$ & 2,103 & $1,381-3,202$ & $\mathbf{0 , 0 0 1}$ \\
\hline
\end{tabular}

Bảng 3.5. Kết quả phân tích hồi quy logistic đa biến các yếu tố tiên lượng độc lập kết cục chức năng tại thời điểm 100 ngày

\begin{tabular}{|l|c|c|c|c|c|c|}
\hline & \multicolumn{3}{|c|}{ Tiên lượng tử vong } & \multicolumn{3}{c|}{ Tiên lượng tàn tật } \\
\hline \multicolumn{1}{|c|}{ Yếu tố } & OR & $\mathbf{9 5 \% C I}$ & $\mathbf{P}$ & OR & $\mathbf{9 5 \% C I}$ & P \\
\hline Tuối & & & & 0,991 & $0,920-1,068$ & 0,816 \\
\hline Giới & & & 0,392 & $0,095-1,612$ & 0,194 \\
\hline Huyết áp tâm thu & 0,997 & $0,964-1,030$ & 0,846 & & & \\
\hline Huyết áp tâm trương & 1,041 & $0,960-1,129$ & 0,329 & & & \\
\hline Thể tích xuất huyết & 0,416 & $0,102-1,704$ & 0,223 & & & \\
\hline Xuất huyết não thất & 0,277 & $0,066-1,162$ & 0,079 & & & 0,673 \\
\hline $\begin{array}{l}\text { Điểm Glasgow lúc } \\
\text { nhập viện }\end{array}$ & 0,967 & $0,698-1,341$ & 0,842 & 0,920 & $0,624-1,356$ & \\
\hline Essen ICH & 2,491 & $1,554-3,995$ & $<\mathbf{0 , 0 0 1}$ & 2 & $1,005-3,979$ & $\mathbf{0 , 0 4 8}$ \\
\hline
\end{tabular}

\section{BÀN LUẦN}

Các thang điểm tiên lượng giữ vai trò quan trọng trong đánh giá và điều trị bệnh nhân với mục tiêu trước hết là cải thiện sự theo dõi cho người bệnh nhằm tránh những chăm sóc không tích cực có thể xảy ra, đồng thời các thang điểm tiên lượng này có thể được sử dụng trong phân tầng nguy cơ, lựa chọn phác đồ điều trị phù hợp và là tiêu chuẩn lựa chọn trong các thiết kế lâm sàng. [10], [11].

Chúng tôi đã tiến hành nghiên cứu giá trị tiên lượng của thang điểm Essen trong tiên lượng bệnh nhân chảy máu não tại bệnh viện Trung ương Huế đồng thời phân tích, so sánh giá trị tiên lượng với một số yếu tố và thang điểm tiên lượng khác trên cỡ mẫu 120 bệnh nhân từ tháng 01/2019 đến tháng 01/2020. Thang điểm Essen gồm ba yếu tố: tuổi, NIHSS, và mức độ ý thức của NIHSS được đưa vào là yếu tố thứ ba với mục đích giải thích cho mức độ nặng ở những bệnh nhân hôn mê và bệnh nhân đặt nội khí quản [9]. Kết quả hồi quy logistics đơn biến và đa biến cho thấy điểm NIHSS là yếu tố có giá trị nhất trong tiên lượng kết cục chức năng của 
bệnh nhân sau chảy máu não tự phát tại thời điểm 100 ngày theo thang điểm Barthel. NIHSS là thang điểm được Hoa Kỳ khuyến cáo sử dụng đối với bệnh nhân đột quỵ não nhằm thống nhất trong đánh giá mức độ nặng của bệnh đối với bệnh nhân, trên cơ sở đó đưa ra thái độ và quyết định điều trị phù hợp [7]. Trong nghiên cứu của chúng tôi điểm NIHSS trung bình của bệnh nhân trong 24 giờ đầu sau nhập viện là $15,17 \pm$ 10,793. Có sự liên quan giữa điểm NIHSS với kết cục chức năng của bệnh nhân với mức ý nghĩa $p<0,05$. Kết cục chức năng của bệnh nhân có xu hướng ngày càng xấu đi theo độ tăng dần của điểm NIHSS.

Trong nghiên cứu của Cinzia Finocchi, mối liên quan giữa điểm NIHSS tại thời điểm nhập viện và kết cục của 156 bệnh nhân chảy máu não thấy điểm NIHSS trung bình tại thời điểm nhập viện là $10,82 \pm 8,27$ thấp hơn so với nghiên cứu của chúng tôi. Có thể do yếu tố thời gian từ khi khởi phát đến khi được thăm khám như bệnh nhân đến muộn, biến của chúng tôi được lấy tại thời điểm trong 24 giờ đầu. Tuy nhiên, tương đồng với chúng tôi, Finocchi tìm thấy mối tương quan có ý nghĩa thống kê giữa điểm NIHSS khi nhập viện và kết cục chức năng của bệnh nhân chảy máu não sau 30 ngày và sau 3 tháng và đưa ra kết luận NIHSS là một công cụ đáng tin cậy để theo dõi lâm sàng và tương quan với tỉ lệ tử vong và chức năng 30 ngày và 3 tháng [5].

Tỉ lệ bệnh nhân tử vong tăng dần theo điểm số của Essen ICH. Essen ICH $=0$ có 93,8\% bệnh nhân hồi phục hoàn toàn, Essen $\mathrm{ICH} \geq 7$ tỉ lệ bệnh nhân tử vong $100 \%$ sau 100 ngày. Ngược lại, điểm Essen ICH càng thấp, tỉ lệ hồi phục hoàn toàn càng cao. Bệnh nhân có điểm Essen $\mathrm{ICH}$ bằng 1 tỉ lệ hồi phục hoàn toàn $66,7 \%$, bệnh nhân có Essen ICH lớn hơn 6 tỉ lệ hồi phục hoàn toàn $0 \%$. Có sự liên quan giữa điểm số Esen $\mathrm{ICH}$ với kết cục chức năng của bệnh nhân sau ICH với p<0,05. Năm 2006 C. Weimar và cộng sự đã nghiên cứu giá trị của thang điểm Essen ICH trên 340 bệnh nhân kết quả cho thấy tỉ lệ bệnh nhân có Essen $\mathrm{ICH}=1$ tî̉ lệ hồi phục hoàn toàn là $71,8 \%$, tử vong là $2,6 \%$. Bệnh nhân có Essen $\mathrm{ICH}=6$ tỉ lệ hồi phục hoàn toàn là $9 \%$, tử vong là $36,6 \%$. Bệnh nhân có Essen ICH lớn hơn hoặc bằng 7 tỉ lệ hồi phục hoàn toàn là $0 \%$, tử vong khi $\mathrm{ICH}$ Essen $=7$ là $63,2 \%$ [9]. Theo kết quả nghiên cứu của chúng tôi, điểm Essen $\mathrm{ICH}$ càng cao thì kết cục chức năng của bệnh nhân càng xấu. Tuy nhiên, bệnh nhân cùng mức điểm Essen ICH của Wiemar có sự hồi phục khả quan hơn so với nghiên cứu của chúng tôi, điều này có thể do nghiên cứu trên mẫu bệnh nhân lớn hơn 340 bệnh nhân, mẫu phân bố trên quần thể lớn, được lấy trên 30 bệnh viên khác nhau cộng với kiến thức, thái độ và nguồn lực trong chăm sóc bệnh nhân ICH sau khi ra viện dẫn đến sự khác biệt về mức độ hồi phục ở bệnh nhân so với nghiên cứu của chúng tôi.

Cho đến nay đã có rất nhiều thang điểm đã được phát triển và xác nhận giá trị của nó trong tiên lượng tử vong, điển hình như thang điểm $\mathrm{ICH}, \mathrm{mICH}$ là hai thang điểm thường được sử dụng, nghiên cứu nhiều nhất cho đến nay. Do đó, trong quá trình thu thập số liệu để đánh giá tiên lượng của thang điểm Essen đối với kết cục chức năng của bệnh nhân tại thời điểm 100 ngày, chúng tôi đồng thời thu thập các số liệu về thang điểm $\mathrm{ICH}$ và $\mathrm{mICH}$ và tiến hành so sánh giá trị tiên lượng của thang điểm Essen với hai thang điểm này và thấy rằng, đối với tiên lượng tử vong cả 3 thang điểm đều cho thấy là những thang điểm có giá trị rất tốt tại thời điểm 100 ngày với AUC lần lượt: Essen ICH $(0,957 ; 95 \%$ CI 0,924-0,989), ICH $(0,941$; 95\%CI $0,899-0,982)$, mICH $(0,952 ; 95 \% \mathrm{CI}$ 0,918-0,986). Trong tiên lượng kết cục tàn tật, Essen ICH tỏ ra là thang điểm vượt trội hơn so với hai thang điểm còn lại với AUC là lượt: $0,934$ (95\%CI $0,893-0,975) ; 0,882 \quad(95 \% \mathrm{CI}$ 0,823-0,942); 0,896 (95\%CI 0,842-0,951).

\section{KẾT LUẬN}

Essen ICH có độ nhạy 82\%, độ đặc hiệu $96,6 \%$ tại điểm cắt 5,5 với Younden's Index 0,786 , diện tích dưới đường cong ROC 0,957 ; $\mathrm{p}<0,001 ; 95 \% \mathrm{CI}$ 0,924- 0,989 trong tiên lượng kết cục tử vong tại thời điểm 100 ngày. Essen ICH có độ nhạy 77,1\%, độ đặc hiệu 94,6\% tại điểm cắt 3,5 với Younden's Index 0,717 , diện tích dưới đường cong ROC 0,$934 ; \mathrm{p}<0,001$; 95\%CI 0,893-0,975 trong tiên lượng kết cục 
tàn tật tại thời điểm 100 ngày.

Đối với tiên lượng kết cục tử vong: cả 3 thang điểm đều cho thấy khả năng tiên lượng rất tốt tại thời điểm 100 ngày với $\mathrm{AUC}$ lần lượt: Essen ICH $(0,957 ; 95 \%$ CI 0,924-0,989), ICH $(0,941 ; 95 \%$ CI 0,899-0,982), $\mathrm{mICH}$ $(0,952 ; 95 \%$ CI $0,918-0,986)$.

Đối với tiên lượng kết cục tàn tật: Essen ICH là thang điểm có khả năng tiên lượng tốt và cao hơn so với thang điểm $\mathrm{ICH}$ và $\mathrm{mICH}$ với AUC lần lượt: 0,934 (95\%CI 0,893-0,975); $0,882(95 \%$ CI $0,823-0,942) ; 0,896 \quad(95 \%$ CI 0,842-0,951). Kết quả phân tích hồi quy logistic đa biến cho thấy Essen ICH là thang điểm có giá trị nhất trong tiên lượng kết cục chức năng tại thời điểm 100 ngày sau xuất huyết não với $\mathrm{OR}=2,491 ; 95 \%$ CI 1,554 $3,995, \mathrm{p}<0,001$ trong tiên lượng kêt cục tử vong và $\mathrm{OR}=2 ; 95 \% \mathrm{CI} 1,005-3,979, \mathrm{p}=0,048$ trong tiên lượng kết cục tàn tật.

\section{TÀI LIỆU THAM KHẢO}

1. Nguyễn Thanh Thảo (2018), "Hình ảnh học các bệnh lí sọ não thường gặp", Đại Học Huế.

2. Sang Joon An (2017), "Epidemiology, Risk Factors, and Clinical Features of Intracerebral Hemorrhage: An Update", Journal of Stroke, 19, 3-10.

3. Emelia J. Benjamin (2019), "Heart Disease and Stroke Statistics: 2019 Update", 281-326.
4. Joseph P. Broderick (1993), "Volume of Intracerebral Hemorrhage A Powerful and Easy-to-Use Predictor of 30-Day Mortality", Stroke 24, 987-993.

5. Cinzia Finocchi (2018), "National Institutes of Health Stroke Scale in patients with primary intracerebral hemorrhage", Neurological Sciences.

6. Tiago Gregório (2018), "Assessment and Comparison of the Four Most Extensively Validated Prognostic Scales for Intracerebral Hemorrhage: Systematic Review with Meta-analysis", Springer Nature and Neurocritical Care Society.

7. J. Claude Hemphill III (2015), "Guidelines for the Management of Spontaneous Intracerebral Hemorrhage", Stroke, 46, 2032-2060.

8. Castillo J (1994), "Prognostic factors in spontaneous intracerebral hemorrhage", An med internal.

9. C Weimar (2006), "Development and validation of the Essen Intracerebral Haemorrhage Score", J Neurol Neurosurg Psychiatry, 77, 601-605.

10. D.B. Zahuranec (2007), "Early care limitations independently predict mortality after intracerebral hemorrhage", Neurology, 68, 1647-1657.

11. J.A. Zurasky (2005), "Early mortality following spontaneous intracerebral hemorrhage", Neurology 64, 725-727. 